\title{
Una propuesta para la modificación del Índice de Desarrollo Humano
}

\author{
Maria Andreina Salas-Bourgoin
}

RESUMEN

El Índice de Desarrollo Humano (IDH) es un indicador diseñado para hacer seguimiento

al desarrollo de los países a través de tres dimensiones: salud, educación e ingresos.

Desde su publicación en 1990, se han hecho importantes esfuerzos por mejorar su calidad y en repetidas ocasiones se ha insistido en que no es una medida definitiva. Atendiendo a este hecho, a continuación se expone una reflexión en torno de lo que es el desarrollo humano, sus pilares y las dimensiones que se deberían incorporar al indicador (empleo y libertades políticas) para reforzar su capacidad de evidenciar los avances en la materia. Además, se presentan el IDH modificado, las especificaciones para su cálculo y un anexo en que se muestra su comportamiento en 117 países.

PALABRAS CLAVE

CLASIFICACIÓN JEL

AUTOR
Desarrollo humano, medición, PNUD, indicadores económicos, indicadores sociales, metodología estadística, datos estadísticos

I31, I32, I39

María Andreina Salas-Bourgoin es profesora asistente con dedicación exclusiva en el Instituto de Geografía y Conservación de Recursos Naturales de la Universidad de Los Andes, Mérida, República Bolivariana de Venezuela.bourgoin@ula.ve 


\section{I}

\section{Introducción}

El Índice de Desarrollo Humano (IDH) es un indicador compuesto, diseñado por el Programa de las Naciones Unidas para el Desarrollo (PNUD) con el propósito de hacer seguimiento a los avances en el desarrollo de los países y ofrecer información útil en el diseño de políticas públicas. Desde su primera publicación en el Informe sobre Desarrollo Humano de 1990, es referencia mundial en la divulgación del desempeño de las naciones en su camino hacia el desarrollo y punto de partida en el establecimiento de clasificaciones.

Por el papel que desempeña este indicador, por ejemplo, en los estudios sobre calidad de vida, equidad y justicia social a diversas escalas, el PNUD ha realizado grandes esfuerzos por mejorar su calidad tanto para reflejar las condiciones de vida de la población, como para evidenciar los avances, estancamientos o retrocesos de una sociedad con respecto a la creación de capacidades, oportunidades y opciones con el fin de que los individuos logren de sí lo que siempre han aspirado.

El año 2010 fue un hito importante en esta labor. En el Informe sobre Desarrollo Humano correspondiente a ese año se publicó, por una parte, el IDH calculado a partir de nuevos indicadores para abordar lo relativo a educación e ingresos y, por otra, el denominado IDH Ajustado por la Desigualdad (IDH-D), en que se valoran las desigualdades existentes en cada una de las dimensiones que conforman el índice original.

Hasta el momento, tres son las dimensiones del IDH: salud, educación e ingresos; y bajo criterios específicos, se intenta una aproximación al carácter multidimensional del desarrollo a través de factores que, por diversas razones, se consideran entre los más condicionantes del proceso de creación de capacidades, oportunidades y opciones: años promedio de educación, años esperados de educación, esperanza de vida al nacer e ingreso nacional bruto per cápita. Sin embargo, en amplios y diversos estudios se da cuenta de que el desarrollo va más allá de los factores mencionados, y que incluye otros como la sostenibilidad ambiental, el empleo o la libertad, igualmente relevantes para estimar los avances en este sentido. Por ello y con el propósito de contribuir a la discusión que estas cuestiones generan, se ha planteado presentar una propuesta de IDH modificado que comprende, sobre la base de una reflexión bibliográfica y estadística, dos dimensiones fundamentales para el desarrollo:

i) El empleo, como condición de la que no solo derivan los ingresos que permiten la satisfacción de necesidades materiales del individuo y la superación de la pobreza, sino también la dignificación del hombre.

ii) La democracia, como forma de gobierno de la que deriva el mayor respeto y garantía de las libertades individuales y colectivas, en consonancia con el desarrollo y la calidad de vida que de este proviene. Es una propuesta que sigue los criterios de selección de indicadores y la lógica de cálculo aplicada por el PNUD. Para el caso del empleo, se propone el uso de dos parámetros: razón entre empleo y población y empleo no vulnerable como porcentaje del empleo total, y para la aproximación a las libertades se plantea el uso del Índice de Democracia (ID).

Con el propósito de ejemplificar la aplicación del IDH modificado y poner en evidencia su utilidad para el análisis de las fortalezas y debilidades del desarrollo en y entre los países, este índice se calcula para el año 2012, tomando como referencia un conjunto de países de diferentes continentes y como fuentes de datos al PNUD, la Organización Internacional del Trabajo (OIT) y la Economist Intelligence Unit (EIU).

Luego de la Introducción, el presente artículo comprende las siguientes secciones: en la sección II se ofrece una breve descripción del desarrollo humano como modelo de desarrollo, con una concepción precisa de lo que este debe ser para el hombre y por el hombre; en la sección III se aborda el Índice de Desarrollo Humano (IDH), indicador por excelencia para estimar los avances en la materia; en la cuarta sección se dan a conocer la bases sobre las que se propone el IDH; en la quinta sección se tratan los temas del empleo y las libertades; en la sección VI se aborda el Índice de Desarrollo Humano modificado, y en la sección VII se entregan las conclusiones. 


\section{II}

\section{El desarrollo humano como modelo de desarrollo}

Desde la década de 1980, con los aportes de Max Neef en materia de desarrollo a escala humana y de Sen, con la concepción del desarrollo como un proceso de expansión de las libertades del ser humano para lograr sus aspiraciones, el hombre se ha convertido en el centro y beneficiario final del desarrollo. El crecimiento económico deja de ser el fin último y, tanto la calidad de vida como la creación de un entorno favorable al logro de objetivos individuales y colectivos, son el propósito a perseguir.

De esta línea de pensamiento surge, a finales de los años ochenta, el desarrollo humano, definido como el proceso de ampliación del abanico de oportunidades y opciones de las personas para que logren una calidad de vida acorde con lo que han soñado y esperado, por medio de la creación de capacidades. Esas capacidades son entendidas como potenciación de habilidades para alcanzar un desarrollo autónomo, para hacer cosas, para existir o para actuar, como señaló Sen en 1988, en su intervención en el Congreso Wider sobre Calidad de Vida $^{1}$ (Vethencourt, 2008).

Según Recalde (1999), el individuo tiene derecho a una oportunidad equitativa para usar sus capacidades. La forma en que aproveche efectivamente las oportunidades ofrecidas por la sociedad y los recursos que obtenga es de su elección, pero en el seno de la sociedad él debe tener la oportunidad de elegir, tanto en el presente como en el futuro. "El propósito básico del desarrollo humano es ampliar las opciones de las personas" (PNUD, 1992).

Para Sen (2000), el desarrollo implica la expansión de cinco tipos de libertad: libertades políticas, facilidades económicas, oportunidades sociales, garantías de transparencia y seguridad protectora. Las libertades políticas se vinculan con los derechos humanos, la posibilidad de seleccionar gobernadores, la libertad de prensa y sin censura, la libertad para organizarse y criticar e investigar a las autoridades.

Las facilidades económicas, por su parte, se refieren a las oportunidades para usar recursos económicos, consumir, producir, realizar intercambios y transacciones. Las oportunidades sociales atañen a los servicios de

1 Conferencia sobre la calidad de vida del Instituto Mundial de Investigaciones de Economía del Desarrollo de las Naciones Unidas. salud, educación y otros, que son esenciales para la población. Las garantías de transparencia aluden a las relaciones fundamentadas en la confianza sobre lo que se ofrece y, finalmente, la seguridad protectora dice relación con la disminución de la vulnerabilidad de las personas (Hernández, 2008).

Según el Informe sobre Desarrollo Humano de 1992, el desarrollo debe ser de, para y por las personas. De esta manera, debe permitir que los individuos puedan intervenir activamente en todos los ámbitos de la vida en sociedad; participar plenamente en la planificación e implementación de acciones orientadas a alcanzar una mejor calidad de vida, y satisfacer sus necesidades en un escenario de oportunidades.

¿A qué se refiere la ampliación de oportunidades y de opciones en el marco del desarrollo humano?

A la creación del escenario requerido por el individuo y el colectivo para materializar una mejor calidad de vida mediante los instrumentos, las herramientas y demás insumos necesarios para que la persona logre los objetivos que se ha planteado y contribuya a alcanzar los de la sociedad en que está inserta.

Las opciones representan el abanico de posibilidades que el individuo puede aprovechar para lograr incrementar su calidad de vida y materializar sus aspiraciones. Como la palabra lo indica, se trata de poder escoger en un contexto que brinda el "...rango más amplio... de cosas que la persona puede hacer o ser, entre las cuales tiene la libertad y la facultad de elegir" (PNUD, 2000).

Según lo anterior: i) las opciones deben ser diversas en calidad y cantidad; ii) la selección entre una u otra opción debe ser facultativa, por tanto el individuo debe tener conciencia o claridad para elegir, dentro del conjunto de lo que se le ofrece, aquello que más se ajusta a sus intereses y sistema de valores, y iii) implica la libertad del individuo para escoger lo que más le conviene.

En materia de oportunidades, el desarrollo humano se refiere a la creación de condiciones, propicias y equitativas, para que la persona pueda hacer uso de las opciones elegidas. Ello sugiere un entorno "que permite", en otras palabras, un contexto donde el individuo y la sociedad, en general, pueden concretar sus aspiraciones porque se les ha dotado de los medios mínimos para ello.

Así, en sociedades con un alto nivel de desarrollo humano es de esperar que las personas puedan elegir y 
tener acceso a los medios que les permitirán materializar o cumplir lo que han elegido; escoger según sus aspiraciones la calidad de vida que desean, así como acceder a los bienes, los servicios y las condiciones de vida, material y espiritual, que contribuirán a materializarla, sin que ello signifique - como bien lo señala el Informe sobre Desarrollo Humano de 1992 - la restricción del acceso a otros u otras generaciones. De allí que deba ser sostenible, inter e intrageneracionalmente.

Según la lógica del desarrollo humano, las opciones y oportunidades son "infinitas", empero, son esenciales: i) una vida prolongada; ii) la adquisición de conocimientos, y iii) el acceso a los recursos requeridos para satisfacer las necesidades básicas o "lograr un nivel de vida decente". Sin embargo, las "distorsiones en el proceso de desarrollo"2 evidencian que la combinación positiva de estos tres factores no siempre conduce al desarrollo, y que también son fundamentales para favorecer el desarrollo individual y colectivo: el pleno empleo, la libertad y la calidad ambiental, entre otros.

Es posible, por ejemplo, que a pesar de un promedio relativamente alto de años de escolarización y, sobre todo, de un alto número de años esperados de escolarización, no existan suficientes opciones para aprovechar las

${ }^{2}$ Alteraciones en el conjunto de cambios que deben sucederse durante el desarrollo. capacidades creadas, debido a que la oferta laboral es restringida, poco diversificada o mal remunerada. En esta situación el desarrollo humano no es elevado, pues aun cuando existe una población capacitada, a ella le acompañan el desempleo, los bajos salarios o un abultado índice de subempleo, debido a un contexto que "limita".

También es posible una sociedad donde la educación y la salud son atendidas adecuadamente y el ingreso nacional bruto per cápita es elevado, pero son restringidos el pluralismo político, la igualdad ante la ley, el debido proceso y la libre expresión. En este caso, el desarrollo humano aunque pareciera alto, no lo es, puesto que la realidad es contraria a lo que el mismo PNUD señala: "La libertad más que un objetivo idealista es un componente vital del desarrollo humano" (PNUD, 1992, pág. 72).

De la misma manera como ocurre en los dos casos anteriores, un desarrollo humano aparentemente alto puede ocultar una calidad de vida material no sostenible, que pone en juego la perdurabilidad de los niveles de vida alcanzados y su garantía a las futuras generaciones.

Este tipo de distorsiones son las que llevan a pensar que el desarrollo humano descansa no solo en la educación, la salud y el ingreso. Es el estadio de una sociedad en que se ofrecen las condiciones apropiadas para que el individuo pueda alcanzar una mayor calidad de vida $y$, entre ellas, el empleo y la libertad son fundamentales. Una desagregación de este enfoque, se muestra en el gráfico 1 .

Desagregación del concepto de desarrollo humano

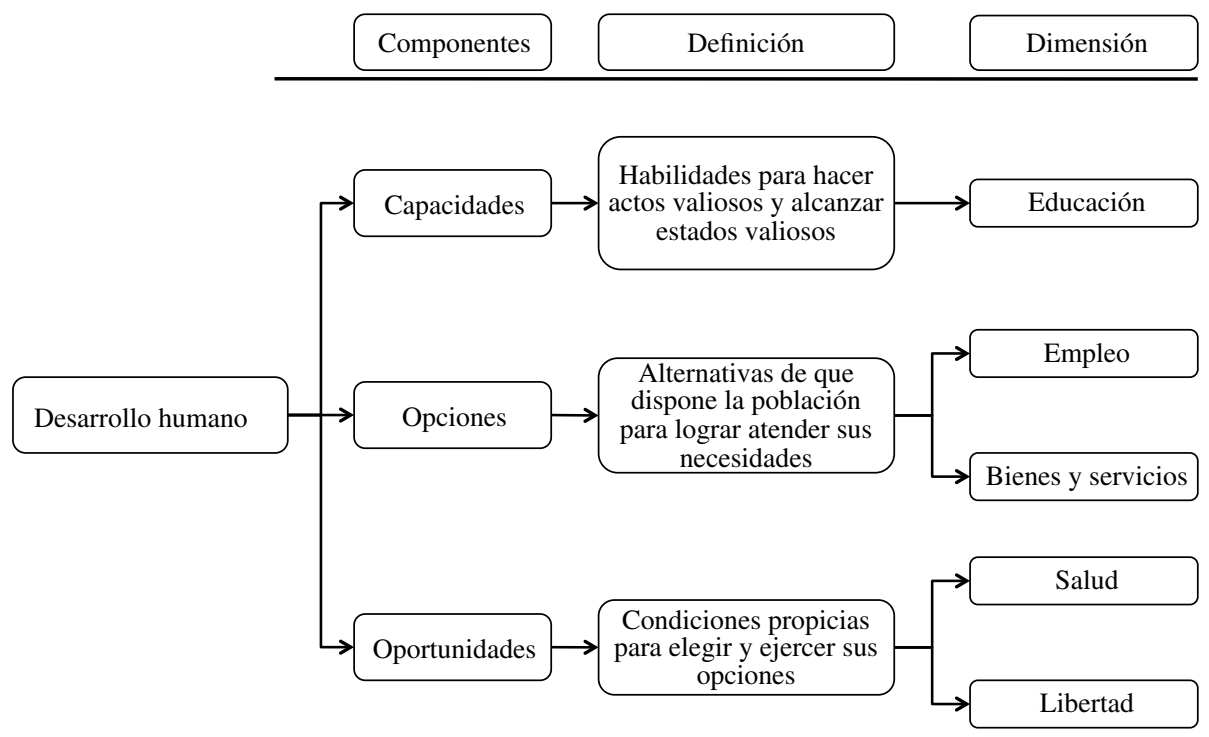

Fuente: elaboración propia. 


\section{III}

\section{Índice de Desarrollo Humano}

A partir del primer Informe sobre Desarrollo Humano de 1990, se publica anualmente el Índice de Desarrollo Humano (IDH) como indicador por excelencia para estimar los avances en la materia y reconocer, dentro del proceso, el desempeño de una sociedad en tres ámbitos esenciales de la vida: salud, educación e ingresos. La salud, valorada por medio de la esperanza de vida al nacer; la educación, a través de los años promedio de escolarización del adulto y los años esperados de escolarización del niño; y los ingresos, a partir del ingreso nacional bruto (INB) per cápita.

Como indicador, es “...una relación matemática que expresa cómo los diversos insumos, tales como niveles de nutrición o escolaridad primaria, producen un determinado nivel de desarrollo humano" (PNUD, 1992, pág. 52). La fórmula para su cálculo es la siguiente:

$$
\mathrm{IDH}=\sqrt[3]{\text { Sub.salud } \times \text { Sub.educación } \times \text { Sub.ingresos }}
$$

donde:

Subíndice de salud: estimado a partir de la esperanza de vida al nacer;

Subíndice de educación: estimado a través de la media geométrica del índice de años promedio de educación del adulto y del índice de años esperados de educación del niño;

Subíndice de ingresos = por medio del ingreso nacional bruto (INB) per cápita.

La fórmula constituye una aproximación cuantitativa a la creación: i) de capacidades, por medio de la educación; ii) de opciones, a partir de la posibilidad de adquirir bienes y servicios, y iii) de oportunidades, a través de la salud.

Entre 1990 y 2009, este indicador se calculó sobre la base de la tasa de alfabetización y de escolarización bruta, la esperanza de vida al nacer y el producto interno bruto (PIB) per cápita. La opinión experta sostuvo que aun cuando era posible incluir más y diversos indicadores para obtener una visión amplia del desarrollo, ello podía generar una imagen confusa de la realidad y debilitar la utilidad del indicador en la formulación de políticas públicas (PNUD, 1990). Por tanto, no se debía "agobiar" al indicador desde el comienzo, pero sí avanzar en su mejoramiento (PNUD, 1992).

Lo relativo a las libertades fue, desde su primera publicación, el punto focal y más candente de las discusiones. Al respecto, en el Informe sobre Desarrollo Humano de 1992 se señaló que “...ninguna medición de la libertad le puede hacer justicia social..." sin embargo, “...aunque muchas de las medidas cuantitativas que se desarrollen no sean más que aproximaciones burdas, pueden constituir un estímulo importante para el pensamiento y el debate" (PNUD, 1992, pág. 72).

En el referido informe se presentó el índice de libertad política (ILP), como indicador focalizado en: i) seguridad personal; ii) imperio de la ley; iii) libertad de expresión; iv) participación política, y v) igualdad de oportunidades. Las conclusiones más relevantes de su estimación fueron, en primer lugar, que: “... la libertad política y el desarrollo humano sí parecen estar estrechamente relacionados. Los países con IDH alto tienen un ILP promedio de $84 \%$, mientras que los países con IDH bajo tienen un ILP promedio de 48\%" (PNUD, 1992, pág. 83); y, en segundo lugar, que el ILP posee una elevada carga subjetiva, centrada en preguntas cuyas respuestas son sí o no, lo que hace necesario seguir afinando el sistema de cuantificación y de ponderación.

En la búsqueda por ampliar la base de indicadores para analizar el estado del desarrollo en un país, los informes sobre desarrollo humano fueron incorporando año tras año indicadores sobre variables fundamentales, llegando a constituirse en anuarios estadísticos sobre temas sensibles como: salud, educación, bienestar, medioambiente, economía y género, entre otros, pero, extrañamente, sin incluir indicadores referidos a la libertad.

Los adelantos se materializaron en el año 2010, cuando el PNUD introdujo modificaciones al IDH que implicaron tanto sustitución de indicadores como cambios en la forma de calcularlo. Manteniendo la misma estructura de las tres dimensiones, se sustituyeron: i) el PIB per cápita por el INB per cápita, y ii) la tasa de alfabetización y de escolarización bruta por los años de educación promedio del adulto y los años esperados de instrucción del niño. De igual manera, se pasó de un método de agregación fundamentado en una media aritmética a uno basado en una media geométrica, redefiniéndose los valores límite empleados para normalizarlo (Klugman, Rodríguez y Choi, 2011).

Según los informes sobre desarrollo humano, las naciones avanzan periódicamente. El cambio en el valor del IDH de los países y su movimiento dentro de la jerarquía mundial así lo muestran. Pero si se toman 
en cuenta los tres nuevos indicadores que reflejan "privaciones y desigualdades" publicados por el PNUD desde el año 2010: Índice de Desarrollo Humano Ajustado por la Desigualdad (IDH-D), Índice de Desigualdad de Género e Índice de Pobreza Multidimensional, tal avance ya no es tan evidente en algunos casos. Lamentablemente, estos índices son manejados independientemente del IDH y, por lo tanto, no influyen en la clasificación según nivel de desarrollo humano. Si los factores que miden fueran incluidos en el IDH junto, por ejemplo, con las libertades, es posible que la jerarquía de países según el desarrollo tuviese otro orden y su dinámica resultaría distinta.

Si el desarrollo humano brinda al individuo los medios necesarios para que logre sus aspiraciones, la libertad es sine qua non. Bien lo señala Sen en su tesis sobre Desarrollo y Libertad (Sen, 2000), para quien la libertad permite que los individuos de una sociedad mejoren de acuerdo con sus deseos y expectativas, y sean más capaces de influir en su entorno.

El empleo es otro factor o dimensión relevante en el desarrollo, no considerado en el IDH. Ni el PIB per cápita, que se utilizaba inicialmente en este indicador, ni el ingreso nacional bruto (INB) per cápita, que se emplea ahora, son reflejo de las opciones para atender las necesidades. El empleo sí lo es, sobre todo porque permite al individuo poner al servicio del bienestar colectivo y propio las capacidades creadas o consolidadas por medio de la educación. Refleja, pues, una sociedad que ofrece diversas fuentes de trabajo para que la persona seleccione la más adecuada a sus aspiraciones y logre, por su intermedio, los recursos que requiere para atender sus necesidades y contribuir al desarrollo nacional.

La oIT sostiene que: “...el trabajo permite a los hogares de bajos recursos superar la pobreza... y la expansión del empleo productivo y decente es la vía hacia el crecimiento y la diversificación de las economías" (OIT, 2012, pág. 1). Asimismo, continúa: "El acceso a un trabajo seguro, productivo y remunerado de manera justa - asalariado o por cuenta propia - es un factor fundamental para la autoestima de las personas y de las familias, que les afirma su sentimiento de pertenencia a una comunidad, y les permite hacer una contribución productiva" (OIT, 2012, pág. 1).

De hecho, el pleno empleo productivo y un trabajo digno para todos, incluidos mujeres y jóvenes, constituye una de las tres metas contempladas en 2005 para lograr el objetivo $\mathrm{N}^{\circ} 1$ de los ocho Objetivos de Desarrollo del Milenio: "Erradicar la pobreza extrema y el hambre". Sin embargo, pese a la relevancia que este tema tiene en la actualidad, no se le hace seguimiento en los informes sobre desarrollo humano, ni en la estimación del IDH.

En el marco de lo que se ha optado por llamar "distorsiones del desarrollo", es posible que en una sociedad el INB per cápita sea elevado debido a la naturaleza de las actividades económicas que realiza, pero que del mismo modo experimente un desempleo que se incrementa truncando la posibilidad de los individuos de lograr sus aspiraciones, e incluso conduciendo al desmejoramiento de las condiciones materiales de vida, sin que ello se refleje en el IDH.

El caso de España ejemplifica la importancia del empleo en el desarrollo humano. Según datos de la oIT (2012), para el cuarto trimestre del año 2011, España presentó una razón entre desempleo y población de $22,8 \%$, que se incrementó 2,5 puntos con relación a la correspondiente al mismo trimestre de 2010. No obstante, indistintamente de esta situación, su IDH aumentó de 0,863 a 0,878 .

Si bien el desarrollo es un proceso de largo plazo cuyos avances se manifiestan lentamente, el IDH varía en forma constante. Ello denota que los cambios en alguna de sus dimensiones repercuten en los valores del indicador. Por consiguiente, ¿el empleo no es una condición que, al cambiar, puede influir también en el desarrollo humano? El desempleo puede ser coyuntural, pero la recuperación de las condiciones originales, por ejemplo, previas a una crisis económica, no es de corto plazo. Hacerle seguimiento es tan importante como la observación de los avances en materia de educación y salud.

El desempleo en España, si bien es producto de una crisis económica que se espera sea de corto plazo, afecta negativamente a la calidad de vida material de los individuos, puesto que representa una contracción de las opciones para satisfacer sus necesidades. Sin embargo, ese impacto no se evidencia en su actual IDH.

Atendiendo a este hecho y aun cuando se reconoce que existen limitaciones para lograr una medida que refleje, integral e integradamente, los avances en el desarrollo humano, se considera posible incorporar otras medidas no manejadas hasta el momento (libertad y empleo) en el IDH para ampliar el espectro de dimensiones consideradas. 


\section{IV}

\section{Bases que justifican la propuesta del IDH}

El IDH es un indicador compuesto que integran otros índices normalizados, cuyos umbrales varían según los avances logrados en el tiempo a medida que el mundo avanza.

El IDH fue diseñado sobre la base de tres dimensiones: salud, educación e INB per cápita, debido a que las dos primeras son condiciones básicas para garantizar un nivel de vida digno, y la última refleja la disponibilidad de recursos para adquirir bienes y servicios. Ahora bien, ¿por qué el IDH se fundamenta solo en tres medidas que, además, tienen un problema común: son promedios que ocultan amplias diferencias en la población? Según diversos informes sobre desarrollo ello se debería a que:

- el exceso de indicadores puede crear una imagen confusa del desarrollo de un país (PNUD, 1990);

- la escasez de información sobre variables potenciales a considerar limita la posibilidad de emplear otros indicadores (PNUD, 1990);

- el IDH está formado por indicadores comprehensivos que dan cuenta de información suministrable por otros indicadores, como por ejemplo, la esperanza de vida al nacer, que se acrecienta si las condiciones vinculadas al control de la mortalidad mejoran (PNUD, 1992), $\mathrm{y}$

- $\quad$ las medidas que son conceptualmente más adecuadas solo se publican para un número reducido de naciones, si se compara con el número de países incluidos en los Informes sobre Desarrollo Humano (Klugman, Rodríguez y Choi, 2011).

Razones más específicas ilustran otros criterios a los que obedece la selección de indicadores que conforman el IDH. Entre ellas, las que se esgrimieron para justificar la discontinuidad del índice de libertad política (ILP): i) que se fundamenta en criterios cualitativos y no en datos empíricos cuantificables; ii) que está dirigido al análisis de un problema complejo con respuestas resumidas (sí o no), sin criterios explicativos, y iii) que se haya limitado para discernir por qué un país clasifica en una categoría y no en otra (PNUD, 1992).

Así, partiendo de estas premisas, el IDH se estructuró de la forma como se muestra en el gráfico 2.

En la actualidad, los avances en el seguimiento mundial de ciertas condiciones, la disponibilidad de estadísticas mundiales manejadas por organismos supranacionales y la estandarización de criterios para la medición de variables dan cuenta de que la realidad ha cambiado, y que la mayor parte de las razones que justificaron un IDH conformado por tres dimensiones perdieron validez. De allí que se sugiera incorporar al índice dos nuevas dimensiones: empleo y libertades.

GRÁFICO 2

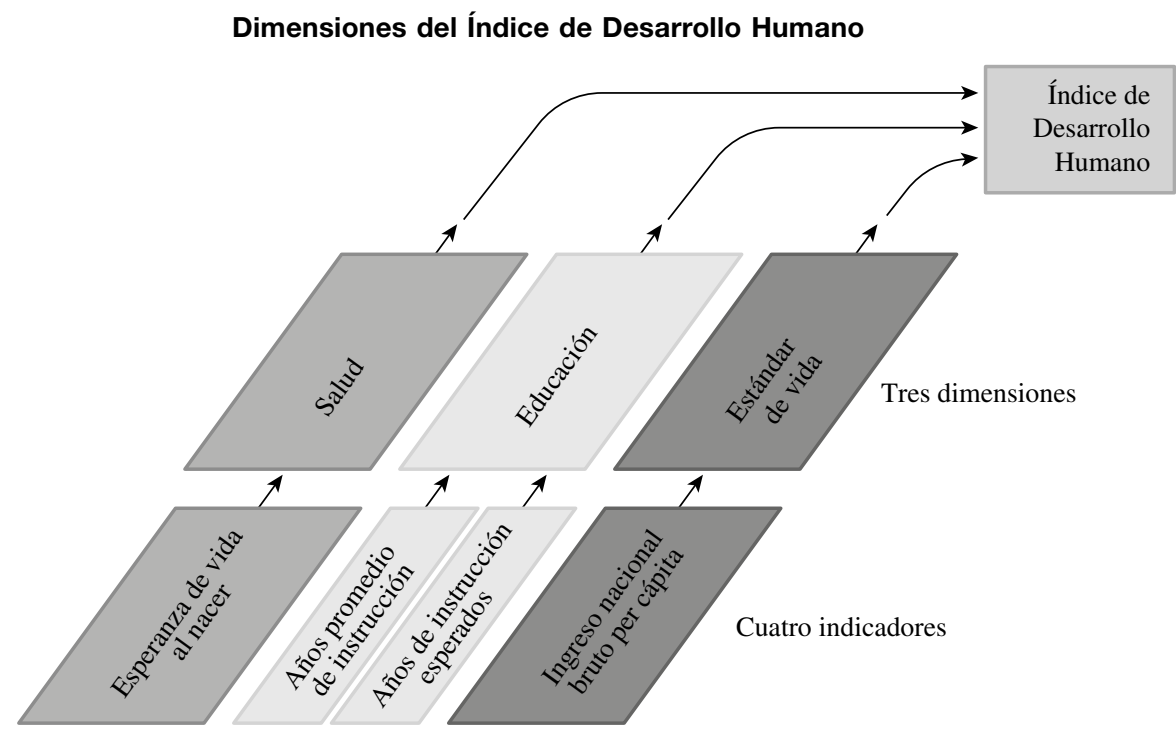

Fuente: elaboración propia sobre la base del Programa de las Naciones Unidas para el Desarrollo (PNUD). 


\section{V}

\section{Empleo y libertades}

Desde el punto de vista teórico, parece posible y hasta necesario incorporar al IDH indicadores que permitan una mejor aproximación a los avances en materia de creación de capacidades y ampliación de opciones y oportunidades en el seno de una sociedad.

Como bien lo señalan Klugman, Rodríguez y Choi: "Los Informes sobre Desarrollo Humano siempre han hecho hincapié en que el IDH no es, y nunca ha pretendido serlo, una medida definitiva del desarrollo...El objetivo es estimular el diálogo y el debate..." (2011, pág. 7). Por lo tanto, explorar otras opciones significa indagar alternativas para lograr un acercamiento cuantitativo más detallado a los niveles de desarrollo humano de una sociedad.

Ello abre camino a múltiples opciones para mejorar el IDH e incorporar, verbigracia, la Huella Ecológica (HE) para evidenciar la sostenibilidad de los patrones de consumo de una sociedad. Sin embargo, en esta ocasión y siguiendo el criterio de no agobiar al indicador, se plantea hacer hincapié en el tema del empleo y las libertades como dos dimensiones fundamentales para sumar al IDH actual, como se muestra en el gráfico 3.

La aproximación a la dimensión del empleo, como reflejo de las opciones en una sociedad, se propone a partir de dos indicadores: i) razón entre empleo y población, y ii) empleo no vulnerable como proporción del empleo total. Por su parte, para la dimensión libertades en tanto reflejo de las oportunidades, se propone el uso del denominado Índice de Democracia (ID); todos ellos aplicados a partir de datos publicados periódicamente por fuentes confiables como la Organización Internacional del Trabajo (OIT) y la Economist Intelligence Unit (EIU).

La razón entre empleo y población en tanto reflejo de las opciones para que el individuo, estando en capacidad de trabajar, encuentre un empleo o ponga en marcha una empresa, y el empleo no vulnerable ${ }^{3}$ como proporción del empleo total, a modo de indicador de una oferta de trabajo que incluye seguridad social apropiada, derecho a la sindicalización, ingresos adecuados y condiciones de trabajo seguras. Se estaría considerando así no solo el empleo, sino también su calidad como bien afirma la OIT, organización para la que el “....desarrollo incluyente y sostenible no será posible si se le niega a millones de personas la oportunidad de ganarse la vida en condiciones dignas y equitativas" (OIT, 2013b, pág. 1).

${ }^{3}$ No incluye al trabajador por cuenta propia ni al ayudante familiar auxiliar.

GRÁFICO 3

Propuesta de IDH modificado

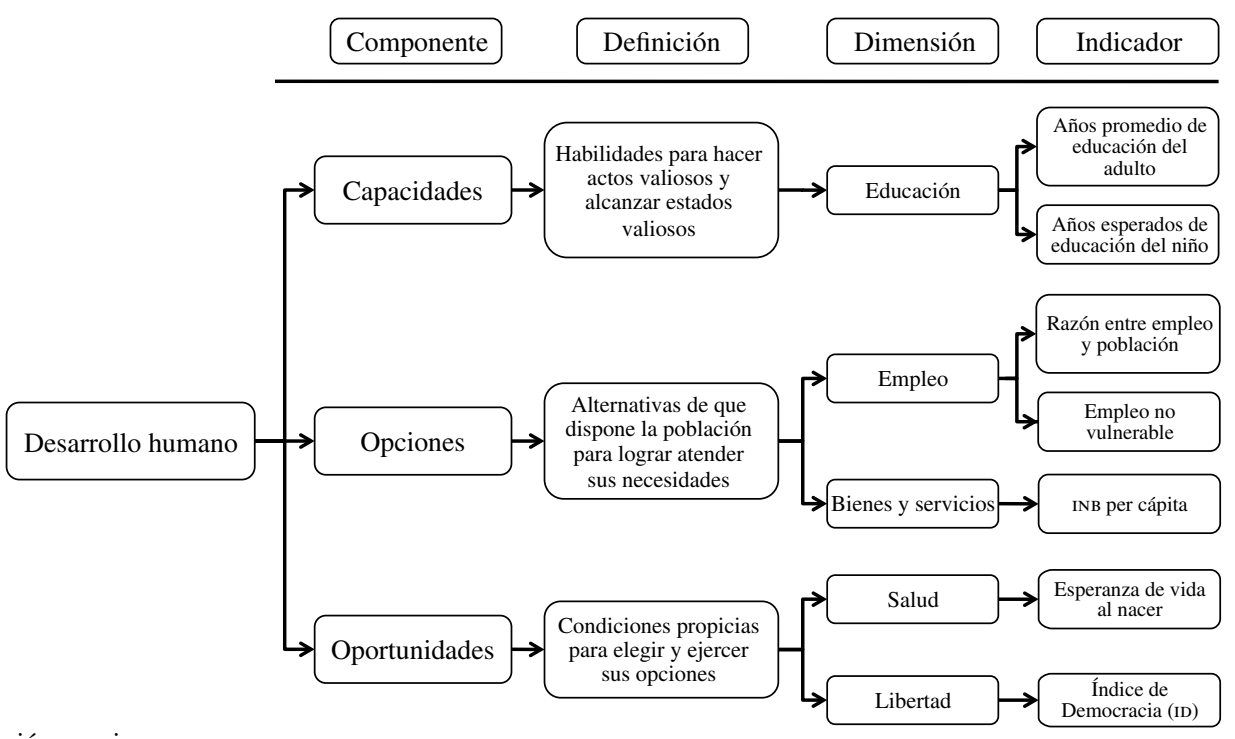

Fuente: elaboración propia.

INB: ingreso nacional bruto.

IDH: Índice de Desarrollo Humano. 
El ID es el indicador del conjunto de libertades políticas que un individuo disfruta en el seno de una sociedad, las que permiten que participe en la formación y administración de las normas e instituciones que lo gobiernan (PNUD, 2002). Según Sen (2000), la democracia propicia que la sociedad dé prioridad a aquello que se propone hacer y, de acuerdo con el PNUD (2002), es no solo un valor sino un medio para lograr el desarrollo.

Publicado por la EIU, este índice fue diseñado para estimar el nivel de democracia de 167 países. Parte de la premisa de que las elecciones libres y las libertades civiles son necesarias para la democracia, pero insuficientes si no están acompañadas de un gobierno transparente y mínimamente eficiente, participación ciudadana y una cultura política democrática (EIU, 2010).

Si bien en los estudios publicados por la misma EIU se sugiere una correlación moderadamente baja entre el ID y el desarrollo económico ${ }^{4}$, la correlación con el IDH es mayor. Estimada para esta propuesta sobre la base de datos de 2012, dio un valor de 0,7 (moderadamente alta), pudiendo considerarse que, si bien no existe una relación perfecta, el desarrollo humano es mayor si hay democracia.

Como indicador, el ID es un promedio simple de respuestas dadas a una encuesta hecha a expertos, fundamentada en 60 preguntas que permiten la clasificación de los países en cuatro categorías claramente diferenciadas y mutuamente excluyentes: i) democracias plenas $(>8)$; ii) democracias en desarrollo $(6-7,9)$; iii) democracias híbridas $(4-5,9)$, y iv) regímenes autoritarios $(<4)$.

En el ID se evalúan cinco componentes: i) 12 indicadores sobre pluralismo y proceso electoral; ii) 14 indicadores relativos al funcionamiento del gobierno; iii) 9 indicadores referidos a participación política; iv) 8

${ }^{4}$ Estimada a partir del logaritmo del PIB per cápita. indicadores sobre cultura política y democrática, y v) 17 indicadores relativos a libertades civiles (Benavides, 2012).

En el marco de cada componente, se suman los puntajes asignados a cada indicador en una escala de 0 a 1 , en la que 0 corresponde a "no", 1 a "sî́" y 0,5 a una condición intermedia cuyo criterio de selección está claramente expuesto en el cuestionario. Por ejemplo: ¿Las elecciones municipales son libres y justas? 1: libres y justas; 0,5 : libres, pero no justas; 0 : ni libres ni justas.

El puntaje obtenido por un país se penaliza si el mismo no puntúa 1 en alguna de estas condiciones clave para la democracia: i) elecciones nacionales libres y justas; ii) seguridad de los votantes; iii) influencia de las potencias extranjeras en el gobierno, y iv) capacidad de la administración pública de implementar sus políticas. $\mathrm{Si}$ el puntaje en las tres primeras condiciones es 0 o 0,5 , se sustrae un punto en "pluralismo y proceso electoral" o en "funcionamiento del gobierno". Si para la cuarta condición el puntaje es 0 , se sustrae un punto en el componente "funcionamiento del gobierno".

En algunos casos, la respuesta negativa a una pregunta inhabilita la posibilidad de responder la siguiente, quedando esta última valorada con 0 . Por ejemplo, si a la pregunta sobre la existencia de elecciones libres, tanto presidenciales como del poder legislativo nacional, la respuesta es "no" (0), automáticamente la siguiente pregunta sobre la justicia de esas elecciones se califica negativamente $(0)$.

Evidentemente, el ID es un indicador subjetivo que no está libre de desacuerdos y de generar controversias; sin embargo, el sistema de asignación de puntajes y de totalización brinda mayor rigurosidad a la cuantificación de una cualidad tan compleja como la democracia. Su ventaja, comparado con indicadores objetivos como el número de votantes, es que intenta aglutinar factores que denotan un régimen democrático y definir, cuantitativamente, las diferencias de uno autoritario.

\section{VI}

\section{Índice de Desarrollo Humano modificado}

Atendiendo al hecho de que el IDH está compuesto por indicadores positivos, es decir, por valores que denotan una característica favorable al desarrollo humano y que, por tanto, su incremento evidencia el mejoramiento de esas condiciones, en esta propuesta se adopta el mismo enfoque. Por consiguiente, se parte de la premisa de que existe una relación positiva entre el empleo, las libertades y el desarrollo; y en tanto que los dos primeros aumenten en esa medida la sociedad habrá ampliado la oferta de opciones y oportunidades para sus miembros. 
La modificación que se propone descansa en la incorporación de tres subíndices al IDH: democracia, empleo y empleo no vulnerable, calculados de igual manera que los de educación y salud.

A objeto de mostrar los pasos para su cálculo, en primer lugar se aborda cada subíndice por medio de un ejemplo $\mathrm{y}$, posteriormente, tomando como referencia datos de la OIT, el PNUD y la EIU, se aplica la fórmula modificada del IDH a un conjunto de países seleccionados por continente.

\section{Subíndice de democracia}

Tomando los datos aportados por el informe de la EIU (2013), se aplica la fórmula que emplea el PNUD para calcular los subíndices del IDH:

$$
\text { Subíndice }=\frac{(\text { valor del país }- \text { valor mínimo })}{(\text { valor máximo }- \text { valor mínimo })}
$$

$\mathrm{Si}$, por ejemplo, el valor máximo del ID es de 9,98 puntos (Noruega, 2010), el mínimo es de 1,08 puntos (República Popular Democrática de Corea, 2012) y se calcula el subíndice de democracia de la Argentina, cuyo ID para ese año es 6,84 puntos, se tiene:

$$
\text { Subíndice de democracia }=\frac{(6,84-1,08)}{(9,98-1,08)}
$$

Subíndice de democracia $=0,647$

\section{Subíndice de empleo y empleo no vulnerable}

En el IDH, la cuestión "educación" — por ejemplo— se aborda mediante un índice combinado que se calcula a través de los años promedio de educación del adulto y los años esperados de educación del niño, tomando como valor mínimo para ambos casos: 0 años.

Como la premisa de los valores mínimos en el IDH es que estos refieran a condiciones de subsistencia, para los fines de establecer los valores mínimos correspondientes a empleo y empleo no vulnerable se revisó la serie de datos para ambos indicadores con respecto al período 2000-2010, que ofrece la séptima edición de Indicadores clave del mercado de trabajo (Key Indicators of the Labour Market).

Entre 2000 y 2010, la razón entre empleo y población más baja en el mundo fue de un $34 \%$. Si durante el período en cuestión la tasa de cambio no extraordinaria de este indicador fue de 5 puntos porcentuales, es posible tomar como umbral mínimo, a escala mundial, un $29 \%$.

Por su parte, con relación al empleo no vulnerable como porcentaje del empleo total ${ }^{5}$, el umbral mínimo para este período es de $5 \%$.

Según lo anterior, los umbrales mínimos para ambos indicadores son diferentes entre sí y, por ello, no es posible estimar un subíndice combinado de empleo, como en el caso de educación. Esto lleva a calcular subíndices individuales para agregarlos al final en la fórmula del IDH.

Un ejemplo permite ilustrar el cálculo de los subíndices de empleo y empleo no vulnerable a partir de los valores mínimos señalados anteriormente y los datos que se presentan en el cuadro 1 .

CUADRO 1

Países seleccionados: razón entre empleo y población y empleo no vulnerable como proporción del empleo total, 2012

\begin{tabular}{lcc}
\hline País & $\begin{array}{c}\text { Razón entre empleo } \\
\text { y población } \\
\text { (en porcentajes) }\end{array}$ & $\begin{array}{c}\text { Empleo no vulnerable } \\
\text { como porcentaje del } \\
\text { empleo total }\end{array}$ \\
\hline Alemania & 56,7 & 93 \\
Colombia & 60,5 & 51 \\
Sri Lanka & 52,3 & 58 \\
\hline
\end{tabular}

Fuente: elaboración propia sobre la base de datos de la Organización Internacional del Trabajo (oIT), "Indicadores clave del mercado de trabajo".

Tomando como umbrales máximos de razón entre empleo y población, 90,1\% (valor reportado por Qatar para 2011) y de empleo no vulnerable como proporción del empleo total, $98 \%$ (valor reportado por Bahrein para 2008), se obtienen los siguientes resultados:

\footnotetext{
${ }^{5}$ La OIT presenta como indicador "empleo vulnerable como porcentaje del empleo total"; partiendo de la premisa de que esta es una proporción, el empleo no vulnerable es la diferencia del primero respecto de 100 . ${ }^{6}$ No aplica el cálculo de una tasa de cambio en el tiempo.
} 


\begin{tabular}{|c|c|c|}
\hline 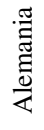 & $\begin{array}{l}\text { Subíndice de empleo }=\frac{56,7-29}{90,1-29} \\
\text { Subíndice de empleo }=0,453\end{array}$ & $\begin{array}{l}\text { Subíndice de empleo }=\frac{93-5}{98-5} \\
\text { Subíndice de empleo }=0,946\end{array}$ \\
\hline$\frac{\frac{\pi}{0}}{\frac{0}{0}}$ & $\begin{array}{l}\text { Subíndice de empleo }=\frac{60,5-29}{90,1-29} \\
\text { Subíndice de empleo }=0,516\end{array}$ & $\begin{array}{l}\text { Subíndice de empleo }=\frac{51-5}{98-5} \\
\text { Subíndice de empleo }=0,495\end{array}$ \\
\hline 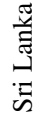 & $\begin{array}{l}\text { Subíndice de empleo }=\frac{52,3-29}{90,1-29} \\
\text { Subíndice de empleo }=0,381\end{array}$ & $\begin{array}{l}\text { Subíndice de empleo }=\frac{58-5}{98-5} \\
\text { Subíndice de empleo }=0,570\end{array}$ \\
\hline
\end{tabular}

Según el ejemplo anterior, en Alemania se evidencian debilidades en la oferta de empleo, pero a la población empleada se le aseguran condiciones laborales adecuadas, productivas y garantes de derechos, a diferencia de Colombia donde estas solo están garantizadas para una porción reducida de la población empleada.

\section{3. Índice de Desarrollo Humano modificado}

Teniendo los subíndices calculados, el IDH modificado sería:

$$
\frac{\text { IDH modificado }=\sqrt[6]{\text { Sub.salud } \times \text { Sub.educación }}}{\times \text { Sub.ingresos } \times \text { Sub.democracia } \times \text { Sub.empleo }}
$$

En el caso de Alemania, tomando datos aportados al PNUD referidos al año 2010, el IDH modificado es:

$$
\begin{aligned}
& I D H \text { modificado }= \\
& \sqrt[6]{0,955 \times 0,944 \times 0,867 \times 0,816 \times 0,453 \times 0,946}
\end{aligned}
$$

$$
\text { IDH modificado }=0,806
$$

En el cuadro 2 se muestran los cálculos del IDH

\begin{tabular}{|c|c|c|c|c|c|c|c|}
\hline País & $\begin{array}{l}\text { Subíndice } \\
\text { de salud }\end{array}$ & $\begin{array}{c}\text { Subíndice } \\
\text { de educación }\end{array}$ & $\begin{array}{l}\text { Subíndice } \\
\text { de ingresos }\end{array}$ & $\begin{array}{c}\text { Subíndice } \\
\text { de democracia }\end{array}$ & $\begin{array}{l}\text { Subíndice } \\
\text { de empleo }\end{array}$ & $\begin{array}{l}\text { Subíndice de } \\
\text { empleo no } \\
\text { vulnerable }\end{array}$ & IDH modificado \\
\hline Noruega & 0,966 & 0,990 & 0,913 & 0,994 & 0,563 & 0,968 & 0,883 \\
\hline Alemania & 0,955 & 0,944 & 0,867 & 0,816 & 0,453 & 0,946 & 0,806 \\
\hline Argentina & 0,884 & 0,815 & 0,743 & 0,647 & 0,450 & 0,817 & 0,709 \\
\hline Brasil & 0,849 & 0,674 & 0,682 & 0,679 & 0,597 & 0,317 & 0,607 \\
\hline Colombia & 0,850 & 0,666 & 0,659 & 0,624 & 0,516 & 0,495 & 0,625 \\
\hline España & 0,972 & 0,871 & 0,821 & 0,780 & 0,255 & 0,892 & 0,706 \\
\hline República de Moldova & 0,783 & 0,714 & 0,517 & 0,589 & 0,177 & 0,710 & 0,527 \\
\hline Paraguay & 0,831 & 0,643 & 0,562 & 0,582 & 0,638 & 0,570 & 0,632 \\
\hline Perú & 0,855 & 0,713 & 0,669 & 0,606 & 0,696 & 0,591 & 0,683 \\
\hline Sri Lanka & 0,870 & 0,723 & 0,582 & 0,525 & 0,381 & 0,570 & 0,589 \\
\hline Turquía & 0,855 & 0,608 & 0,726 & 0,526 & 0,277 & 0,677 & 0,578 \\
\hline Uruguay & 0,902 & 0,764 & 0,722 & 0,797 & 0,537 & 0,785 & 0,742 \\
\hline Venezuela (República & 0,861 & 0,697 & 0,700 & 0,457 & 0,524 & 0,667 & 0,637 \\
\hline \multicolumn{8}{|l|}{ Bolivariana de) } \\
\hline Federación de Rusia & 0,774 & 0,862 & 0,734 & 0,299 & 0,501 & 0,957 & 0,642 \\
\hline
\end{tabular}
modificado para países seleccionados.

Comparando el IDH con la propuesta de modificación, se obtienen el cuadro 3 y el gráfico 4 .

CUADRO 2

Países seleccionados: IDH modificado, 2012

Fuente: elaboración propia sobre la base de datos del Programa de las Naciones Unidas para el Desarrollo (PNUD) y de la Organización Internacional del Trabajo (OIT), "Informe sobre el trabajo en el mundo, 2012. Resumen de España”, 2012 [en línea] http://www.ilo.org/ wcmsp5/groups/public/---dgreports/---dcomm/documents/briefingnote/wcms_179517.pdf. 
CUADRO 3

Países seleccionados: IDH e IDH modificado, 2012

\begin{tabular}{|c|c|c|c|c|c|}
\hline País & IDH & Jerarquía $^{a}$ & IDH modificado & Jerarquía b & Diferencia \\
\hline Noruega & 0,955 & 1 & 0,883 & 1 & 0,072 \\
\hline Alemania & 0,920 & 5 & 0,806 & 7 & 0,114 \\
\hline Argentina & 0,811 & 45 & 0,709 & 28 & 0,102 \\
\hline Brasil & 0,730 & 85 & 0,607 & 54 & 0,123 \\
\hline Colombia & 0,719 & 91 & 0,625 & 50 & 0,094 \\
\hline España & 0,885 & 30 & 0,706 & 23 & 0,179 \\
\hline República de Moldova & 0,660 & 113 & 0,527 & 74 & 0,133 \\
\hline Paraguay & 0,669 & 111 & 0,632 & 47 & 0,037 \\
\hline Perú & 0,741 & 74 & 0,683 & 34 & 0,058 \\
\hline Sri Lanka & 0,715 & 92 & 0,589 & 60 & 0,126 \\
\hline Turquía & 0,722 & 90 & 0,578 & 62 & 0,144 \\
\hline Uruguay & 0,792 & 51 & 0,742 & 21 & 0,050 \\
\hline Venezuela (República Bolivariana de) & 0,748 & 71 & 0,637 & 47 & 0,111 \\
\hline Federación de Rusia & 0,778 & 55 & 0,642 & 43 & 0,136 \\
\hline
\end{tabular}

Fuente: elaboración propia sobre la base de datos del Programa de las Naciones Unidas para el Desarrollo (PNUD).

a Jerarquía entre 187 países (PNUD-2013).

b Jerarquía entre 117 países (cálculos propios).

GRÁFICO 4

Países seleccionados: IDH e IDH modificado, 2012

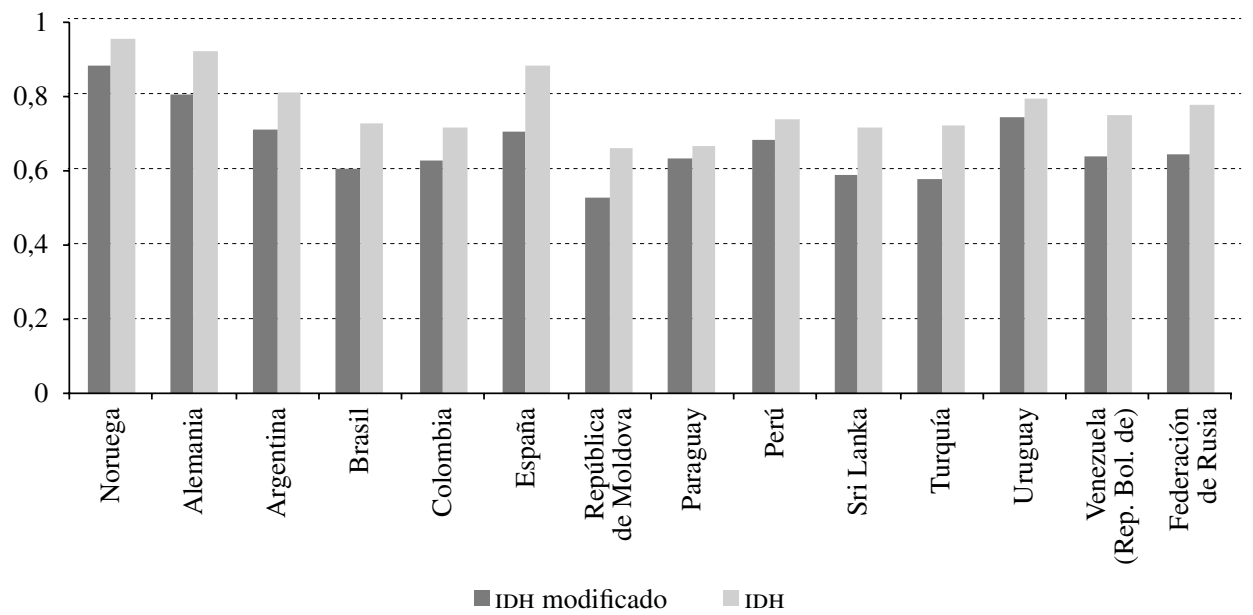

Fuente: elaboración propia.

De los cuadros 2 y 3 , así como del gráfico 4 , es importante resaltar que:

i) Todos los países muestran un menor desarrollo humano, según el IDH modificado.

ii) La mayor fortaleza en materia de desarrollo humano es la salud, mientras que el empleo es la mayor debilidad según el enfoque propuesto.

iii) Los países con IDH alto, como Noruega y Alemania, tienen un IDH modificado menor, debido al subíndice de empleo. Si bien estos países son los que tienen la mayor oferta de empleo no vulnerable, evidencian debilidades en la capacidad de garantizar el empleo a la población en edad de trabajar.

iv) $\mathrm{Al}$ contrario de este comportamiento, los países con IDH medio y bajo muestran debilidades tanto en la oferta de empleo como en la de empleo no vulnerable.

v) España y la República de Moldova son los casos más sensibles con respecto a la influencia del empleo en el desarrollo humano, según este enfoque. 
vi) Venezuela (República Bolivariana de) y la Federación de Rusia son los países, entre el conjunto seleccionado, en los que el subíndice de democracia tiene mayor influencia al estimar el IDH modificado, especialmente en el último país.

Con relación a la jerarquía de países o el lugar que ocupa cada país en la clasificación según IDH e IDH modificado $^{7}$, se constata que:

i) Noruega es el único país que mantiene la misma posición.

ii) Países como Alemania y España bajan de posición en la jerarquía, principalmente debido a la influencia del empleo en el IDH modificado. El primero, es superado por Dinamarca, Suecia y Suiza; el segundo, por la Argentina, Panamá, Portugal, Lituania y Eslovaquia, por ejemplo.

iii) Los Emiratos Árabes Unidos y la Federación de Rusia bajan de posición, pero en este caso debido

\footnotetext{
7 Véase el cuadro A.1 del anexo estadístico.
}

\section{VII}

\section{Conclusiones}

El IDH modificado es una propuesta cuyo objetivo es promover una discusión en torno de cómo mejorar la capacidad del IDH para aproximarse a los avances en el desarrollo humano.

Se sustenta en dos nuevas dimensiones que se consideran fundamentales en la creación y ampliación de opciones y oportunidades: el empleo y las libertades, utilizando para ello tres indicadores derivados de fuentes confiables, disponibles para los países a los que el PNUD les hace seguimiento periódico: i) razón entre empleo y población; ii) empleo no vulnerable como proporción del empleo total, y iii) Índice de Democracia. La relación de estos indicadores con el desarrollo humano ha sido reconocida.

Su cálculo sigue la misma lógica del IDH, de allí que sea la media geométrica de los subíndices que lo componen; de este modo, al disponer individualmente de estos subíndices, es posible reconocer cuáles son las debilidades y fortalezas del desarrollo humano en un país. a la democracia. Ello da lugar a que sean superados dentro de la jerarquía de países, en el caso de los Emiratos Árabes Unidos, por Jamaica, Trinidad y Tabago, la Argentina y Costa Rica, y en el de la Federación de Rusia por el Perú, Malasia y Jamaica, entre otros.

iv) Botswana y Tailandia son un caso relevante a señalar, puesto que ascienden sensiblemente en la jerarquía del IDH modificado, gracias a que presentan subíndices de empleo, empleo no vulnerable y democracia similares a los de los países desarrollados. Ello permite que se ubiquen en el puesto 44 y 48 , respectivamente, dentro de un grupo de 117 países, y que superen a Venezuela (República Bolivariana de), Turquía, el Ecuador, Grecia, el Brasil y Bulgaria,

v) La última posición es ocupada por el Chad debido a dos razones particulares: bajo subíndice de democracia $(0,061)$ y muy bajo subíndice de empleo no vulnerable $(0,011)$, los que inciden en que su IDH modificado sea 0,158 .

Las dos dimensiones incorporadas se muestran sensibles para resaltar las diferencias entre países y hacer una mejor "fotografía" del desarrollo humano. Muestra de ello es el caso de los países con IDH alto cuya debilidad, desde la perspectiva del IDH modificado, radica sobre todo en el empleo, mientras que en los países no desarrollados estriba en la calidad del empleo.

También el IDH modificado se muestra sensible a la democracia. Países como la Federación de Rusia y Venezuela (República Bolivariana de), cuyo IDH actualmente es alto, evidencian un desarrollo humano menguado por libertades políticas limitadas. Condición que también se puede apreciar en la Arabia Saudita y en China, por ejemplo.

El IDH modificado, calculado para países seleccionados, muestra un valor inferior al IDH. Esto no desestima los logros en materia de desarrollo humano, sino que brinda una especie de "lente de aumento" para observar con más detalle dónde están las debilidades o las fortalezas. 
ANEXO ESTADÍSTICO

Con el objetivo de mostrar los cambios en la jerarquía de países según el IDH modificado, en el cuadro A.1 se presentan los valores de cada uno de los subíndices, el
IDH modificado, y la posición que ocupa cada país según este y según el IDH.

Índice de Desarrollo Humano modificado, 2012

\begin{tabular}{|c|c|c|c|c|c|c|c|c|c|}
\hline & 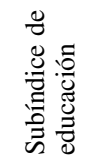 & 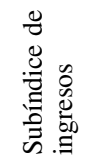 & 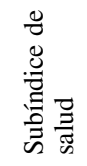 & 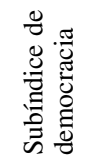 & 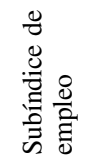 & 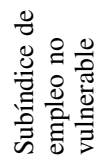 & 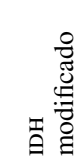 & $\mathrm{a}$ & $\mathrm{b}$ \\
\hline Noruega & 0,99 & 0,913 & 0,966 & 0,994 & 0,563 & 0,968 & 0,883 & 1 & 1 \\
\hline Islandia & 0,912 & 0,838 & 0,977 & 0,963 & 0,658 & 0,935 & 0,873 & 2 & 14 \\
\hline Suiza & 0,873 & 0,886 & 0,985 & 0,900 & 0,591 & 0,925 & 0,849 & 3 & 9 \\
\hline Suecia & 0,913 & 0,87 & 0,971 & 0,972 & 0,491 & 0,946 & 0,839 & 4 & 8 \\
\hline Dinamarca & 0,92 & 0,858 & 0,93 & 0,948 & 0,488 & 0,957 & 0,829 & 5 & 15 \\
\hline Estados Unidos de América & 0,994 & 0,897 & 0,926 & 0,790 & 0,475 & 0,968 & 0,818 & 6 & 3 \\
\hline Alemania & 0,944 & 0,867 & 0,955 & 0,816 & 0,453 & 0,946 & 0,806 & 7 & 5 \\
\hline Austria & 0,859 & 0,871 & 0,962 & 0,847 & 0,475 & 0,925 & 0,803 & 8 & 18 \\
\hline Japón & 0,888 & 0,854 & 1,000 & 0,787 & 0,450 & 0,968 & 0,799 & 9 & 11 \\
\hline Finlandia & 0,88 & 0,854 & 0,949 & 0,897 & 0,432 & 0,914 & 0,795 & 10 & 20 \\
\hline Luxemburgo & 0,778 & 0,912 & 0,948 & 0,876 & 0,406 & 0,957 & 0,782 & 11 & 26 \\
\hline Reino Unido & 0,828 & 0,854 & 0,951 & 0,801 & 0,457 & 0,892 & 0,777 & 12 & 27 \\
\hline Irlanda & 0,964 & 0,835 & 0,958 & 0,840 & 0,378 & 0,892 & 0,776 & 13 & 7 \\
\hline Singapur & 0,804 & 0,925 & 0,966 & 0,539 & 0,574 & 0,925 & 0,768 & 14 & 19 \\
\hline \multicolumn{10}{|l|}{ Hong Kong (Región Administrativa } \\
\hline Especial de China) & 0,831 & 0,904 & 0,994 & 0,600 & 0,458 & 0,957 & 0,762 & 15 & 13 \\
\hline Estonia & 0,919 & 0,762 & 0,868 & 0,734 & 0,448 & 0,968 & 0,761 & 16 & 34 \\
\hline República Checa & 0,916 & 0,797 & 0,912 & 0,799 & 0,419 & 0,860 & 0,759 & 17 & 28 \\
\hline Eslovenia & 0,936 & 0,809 & 0,938 & 0,764 & 0,391 & 0,882 & 0,756 & 18 & 22 \\
\hline Francia & 0,871 & 0,843 & 0,973 & 0,764 & 0,350 & 0,946 & 0,752 & 19 & 21 \\
\hline Bélgica & 0,89 & 0,858 & 0,947 & 0,783 & 0,329 & 0,914 & 0,744 & 20 & 17 \\
\hline Uruguay & 0,764 & 0,722 & 0,902 & 0,797 & 0,537 & 0,785 & 0,742 & 21 & 51 \\
\hline Malta & 0,816 & 0,791 & 0,944 & 0,809 & 0,319 & 0,925 & 0,725 & 22 & 32 \\
\hline Costa Rica & 0,713 & 0,692 & 0,937 & 0,789 & 0,481 & 0,806 & 0,722 & 23 & 62 \\
\hline Trinidad y Tabago & 0,698 & 0,796 & 0,794 & 0,664 & 0,553 & 0,849 & 0,719 & 24 & 68 \\
\hline Eslovaquia & 0,87 & 0,78 & 0,878 & 0,704 & 0,360 & 0,892 & 0,716 & 25 & 35 \\
\hline Lituania & 0,873 & 0,757 & 0,829 & 0,692 & 0,375 & 0,925 & 0,713 & 26 & 41 \\
\hline Portugal & 0,741 & 0,781 & 0,942 & 0,769 & 0,375 & 0,839 & 0,713 & 27 & 43 \\
\hline Panamá & 0,741 & 0,724 & 0,888 & 0,674 & 0,561 & 0,710 & 0,710 & 28 & 60 \\
\hline Argentina & 0,815 & 0,743 & 0,884 & 0,647 & 0,450 & 0,817 & 0,709 & 29 & 45 \\
\hline Letonia & 0,868 & 0,737 & 0,846 & 0,671 & 0,367 & 0,946 & 0,708 & 30 & 44 \\
\hline España & 0,871 & 0,821 & 0,972 & 0,780 & 0,255 & 0,892 & 0,706 & 31 & 23 \\
\hline Mauricio & 0,659 & 0,722 & 0,844 & 0,797 & 0,430 & 0,860 & 0,701 & 32 & 80 \\
\hline Polonia & 0,819 & 0,765 & 0,888 & 0,679 & 0,352 & 0,828 & 0,692 & 33 & 39 \\
\hline Malasia & 0,731 & 0,726 & 0,859 & 0,599 & 0,484 & 0,785 & 0,686 & 34 & 65 \\
\hline Perú & 0,713 & 0,669 & 0,855 & 0,606 & 0,696 & 0,591 & 0,683 & 35 & 77 \\
\hline Italia & 0,852 & 0,822 & 0,977 & 0,748 & 0,234 & 0,828 & 0,680 & 36 & 25 \\
\hline Hungría & 0,89 & 0,75 & 0,862 & 0,661 & 0,270 & 0,957 & 0,679 & 37 & 37 \\
\hline Kuwait & 0,62 & 0,925 & 0,863 & 0,303 & 0,614 & 1,000 & 0,672 & 38 & 54 \\
\hline Rumania & 0,821 & 0,694 & 0,855 & 0,613 & 0,376 & 0,688 & 0,653 & 39 & 56 \\
\hline Croacia & 0,784 & 0,744 & 0,896 & 0,657 & 0,250 & 0,849 & 0,647 & 40 & 47 \\
\hline Jamaica & 0,748 & 0,621 & 0,841 & 0,709 & 0,421 & 0,624 & 0,646 & 41 & 86 \\
\hline Emiratos Árabes Unidos & 0,686 & 0,894 & 0,894 & 0,169 & 0,769 & 1,011 & 0,645 & 42 & 42 \\
\hline Federación de Rusia & 0,862 & 0,734 & 0,774 & 0,299 & 0,501 & 0,957 & 0,642 & 43 & 55 \\
\hline Botswana & 0,683 & 0,72 & 0,521 & 0,761 & 0,561 & 0,634 & 0,641 & 44 & 119 \\
\hline Ecuador & 0,679 & 0,637 & 0,88 & 0,528 & 0,599 & 0,570 & 0,640 & 45 & 89 \\
\hline Grecia & 0,856 & 0,786 & 0,947 & 0,738 & 0,205 & 0,699 & 0,638 & 46 & 29 \\
\hline Venezuela (República Bolivariana de) & 0,697 & 0,7 & 0,861 & 0,457 & 0,524 & 0,667 & 0,637 & 47 & 71 \\
\hline Paraguay & 0,643 & 0,562 & 0,831 & 0,582 & 0,638 & 0,570 & 0,632 & 48 & 111 \\
\hline Tailandia & 0,599 & 0,642 & 0,856 & 0,615 & 0,687 & 0,452 & 0,630 & 49 & 103 \\
\hline Kazajstán & 0,839 & 0,686 & 0,747 & 0,322 & 0,638 & 0,699 & 0,629 & 50 & 69 \\
\hline Colombia & 0,666 & 0,659 & 0,85 & 0,624 & 0,516 & 0,495 & 0,625 & 51 & 91 \\
\hline República Dominicana & 0,625 & 0,656 & 0,846 & 0,608 & 0,444 & 0,624 & 0,623 & 52 & 96 \\
\hline El Salvador & 0,634 & 0,602 & 0,827 & 0,606 & 0,468 & 0,613 & 0,616 & 53 & 107 \\
\hline Bahrein & 0,748 & 0,776 & 0,87 & 0,174 & 0,589 & 1,000 & 0,611 & 54 & 48 \\
\hline Brasil & 0,674 & 0,682 & 0,849 & 0,679 & 0,597 & 0,317 & 0,607 & 55 & 85 \\
\hline Filipinas & 0,679 & 0,535 & 0,773 & 0,587 & 0,509 & 0,591 & 0,606 & 56 & 114 \\
\hline
\end{tabular}




\begin{tabular}{|c|c|c|c|c|c|c|c|c|c|}
\hline & 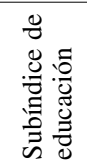 & 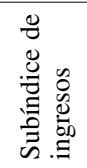 & 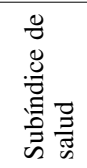 & 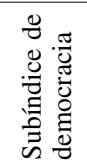 & 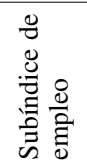 & 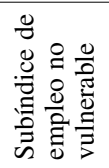 & 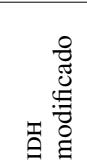 & $\mathrm{a}$ & b \\
\hline Cabo Verde & 0,445 & 0,529 & 0,856 & 0,769 & 0,535 & 0,591 & 0,605 & 57 & 132 \\
\hline Serbia & 0,787 & 0,673 & 0,862 & 0,590 & 0,244 & 0,742 & 0,604 & 58 & 64 \\
\hline Bolivia (Estado Plurinacional de) & 0,743 & 0,56 & 0,74 & 0,535 & 0,678 & 0,430 & 0,603 & 59 & 108 \\
\hline Bulgaria & 0,81 & 0,7 & 0,845 & 0,634 & 0,291 & 0,518 & 0,598 & 60 & 57 \\
\hline Sri Lanka & 0,723 & 0,582 & 0,87 & 0,525 & 0,381 & 0,570 & 0,589 & 61 & 92 \\
\hline Mongolia & 0,726 & 0,553 & 0,769 & 0,592 & 0,501 & 0,409 & 0,578 & 62 & 108 \\
\hline Turquía & 0,608 & 0,726 & 0,855 & 0,526 & 0,277 & 0,677 & 0,578 & 63 & 90 \\
\hline Indonesia & 0,577 & 0,55 & 0,785 & 0,638 & 0,558 & 0,409 & 0,575 & 64 & 121 \\
\hline Honduras & 0,575 & 0,522 & 0,842 & 0,535 & 0,504 & 0,452 & 0,560 & 65 & 120 \\
\hline Viet Nam & 0,539 & 0,501 & 0,874 & 0,203 & 0,764 & 0,839 & 0,560 & 66 & 127 \\
\hline Guatemala & 0,439 & 0,553 & 0,811 & 0,539 & 0,592 & 0,484 & 0,559 & 67 & 133 \\
\hline Sudáfrica & 0,705 & 0,674 & 0,526 & 0,754 & 0,173 & 0,914 & 0,557 & 68 & 121 \\
\hline Fiji & 0,812 & 0,548 & 0,779 & 0,291 & 0,458 & 0,602 & 0,551 & 69 & 96 \\
\hline Líbano & 0,699 & 0,711 & 0,833 & 0,446 & 0,209 & 0,720 & 0,551 & 69 & 72 \\
\hline ex República Yugoeslava de & & & & & & & & & \\
\hline Macedonia & 0,697 & 0,67 & 0,868 & 0,571 & 0,154 & 0,785 & 0,551 & 69 & 78 \\
\hline Kirguistán & 0,721 & 0,443 & 0,758 & 0,406 & 0,535 & 0,516 & 0,548 & 70 & 125 \\
\hline Nicaragua & 0,527 & 0,478 & 0,856 & 0,503 & 0,484 & 0,516 & 0,548 & 70 & 129 \\
\hline Túnez & 0,646 & 0,649 & 0,863 & 0,516 & 0,203 & 0,710 & 0,547 & 71 & 94 \\
\hline República de Moldova & 0,714 & 0,517 & 0,783 & 0,589 & 0,177 & 0,710 & 0,527 & 72 & 113 \\
\hline Azerbaiyán & 0,76 & 0,65 & 0,802 & 0,233 & 0,542 & 0,430 & 0,527 & 72 & 82 \\
\hline Egipto & 0,587 & 0,589 & 0,843 & 0,391 & 0,231 & 0,774 & 0,523 & 73 & 112 \\
\hline Bhután & 0,356 & 0,585 & 0,75 & 0,401 & 0,668 & 0,452 & 0,516 & 74 & 140 \\
\hline Namibia & 0,557 & 0,604 & 0,672 & 0,580 & 0,213 & 0,667 & 0,515 & 75 & 128 \\
\hline Camboya & 0,52 & 0,449 & 0,687 & 0,436 & 0,858 & 0,290 & 0,509 & 76 & 138 \\
\hline Armenia & 0,763 & 0,593 & 0,858 & 0,338 & 0,213 & 0,613 & 0,508 & 77 & 87 \\
\hline Gabón & 0,659 & 0,713 & 0,68 & 0,301 & 0,362 & 0,452 & 0,500 & 78 & 106 \\
\hline Timor-Leste & 0,48 & 0,59 & 0,677 & 0,683 & 0,417 & 0,269 & 0,495 & 79 & 134 \\
\hline Lesotho & 0,501 & 0,433 & 0,453 & 0,627 & 0,813 & 0,280 & 0,491 & 80 & 158 \\
\hline Argeria & 0,679 & 0,636 & 0,842 & 0,309 & 0,172 & 0,710 & 0,489 & 81 & 93 \\
\hline Ghana & 0,596 & 0,417 & 0,703 & 0,555 & 0,620 & 0,215 & 0,485 & 82 & 135 \\
\hline Jordania & 0,697 & 0,585 & 0,844 & 0,304 & 0,133 & 0,914 & 0,483 & 83 & 100 \\
\hline Kenya & 0,584 & 0,404 & 0,594 & 0,408 & 0,517 & 0,344 & 0,465 & 84 & 145 \\
\hline Bosnia y Herzegovina & 0,705 & 0,641 & 0,88 & 0,453 & 0,070 & 0,753 & 0,461 & 85 & 81 \\
\hline India & 0,459 & 0,515 & 0,722 & 0,724 & 0,403 & 0,151 & 0,442 & 86 & 136 \\
\hline Nepal & 0,358 & 0,359 & 0,774 & 0,346 & 0,863 & 0,247 & 0,441 & 87 & 157 \\
\hline Swazilandia & 0,583 & 0,581 & 0,456 & 0,238 & 0,244 & 0,796 & 0,439 & 88 & 141 \\
\hline Senegal & 0,402 & 0,414 & 0,625 & 0,563 & 0,660 & 0,183 & 0,438 & 89 & 154 \\
\hline Pakistán & 0,397 & 0,479 & 0,721 & 0,392 & 0,357 & 0,344 & 0,433 & 90 & 146 \\
\hline Bangladesh & 0,415 & 0,425 & 0,777 & 0,537 & 0,630 & 0,108 & 0,413 & 91 & 146 \\
\hline Zambia & 0,503 & 0,385 & 0,464 & 0,582 & 0,622 & 0,151 & 0,412 & 92 & 163 \\
\hline Camerún & 0,534 & 0,45 & 0,507 & 0,265 & 0,640 & 0,204 & 0,402 & 93 & 150 \\
\hline República Democrática del Congo & 0,515 & 0,499 & 0,596 & 0,203 & 0,596 & 0,215 & 0,398 & 94 & 142 \\
\hline República Islámica del Iran & 0,707 & 0,69 & 0,839 & 0,101 & 0,169 & 0,570 & 0,398 & 94 & 76 \\
\hline Malawi & 0,443 & 0,302 & 0,549 & 0,562 & 0,782 & 0,118 & 0,395 & 95 & 170 \\
\hline Zimbabwe & 0,571 & 0,213 & 0,516 & 0,179 & 0,877 & 0,355 & 0,389 & 96 & 172 \\
\hline Madagascar & 0,49 & 0,312 & 0,74 & 0,320 & 0,894 & 0,097 & 0,383 & 97 & 151 \\
\hline Liberia & 0,429 & 0,232 & 0,589 & 0,435 & 0,493 & 0,280 & 0,390 & 98 & 174 \\
\hline Guinea & 0,249 & 0,331 & 0,545 & 0,192 & 0,668 & 0,484 & 0,375 & 99 & 178 \\
\hline Guinea Ecuatorial & 0,433 & 0,794 & 0,495 & 0,084 & 0,823 & 0,183 & 0,359 & 100 & 136 \\
\hline República Árabe de Siria & 0,544 & 0,568 & 0,883 & 0,062 & 0,164 & 0,667 & 0,350 & 101 & 116 \\
\hline Benin & 0,367 & 0,394 & 0,576 & 0,553 & 0,707 & 0,054 & 0,347 & 102 & 166 \\
\hline República Democrática Popular Lao & 0,453 & 0,471 & 0,754 & 0,139 & 0,782 & 0,075 & 0,331 & 103 & 138 \\
\hline Togo & 0,498 & 0,329 & 0,592 & 0,266 & 0,745 & 0,065 & 0,328 & 104 & 159 \\
\hline Mozambique & 0,222 & 0,325 & 0,485 & 0,427 & 0,797 & 0,075 & 0,311 & 105 & 185 \\
\hline Malí & 0,257 & 0,316 & 0,502 & 0,454 & 0,319 & 0,129 & 0,302 & 106 & 182 \\
\hline Etiopía & 0,289 & 0,342 & 0,627 & 0,297 & 0,823 & 0,043 & 0,294 & 107 & 173 \\
\hline Rwanda & 0,403 & 0,36 & 0,564 & 0,256 & 0,925 & 0,032 & 0,292 & 108 & 167 \\
\hline Níger & 0,177 & 0,287 & 0,553 & 0,346 & 0,530 & 0,108 & 0,287 & 109 & 186 \\
\hline Burkina Faso & 0,196 & 0,367 & 0,566 & 0,274 & 0,851 & 0,054 & 0,283 & 110 & 183 \\
\hline Sierra Leona & 0,326 & 0,321 & 0,444 & 0,408 & 0,604 & 0,032 & 0,268 & 111 & 177 \\
\hline Chad & 0,223 & 0,374 & 0,471 & 0,061 & 0,614 & 0,011 & 0,158 & 112 & 184 \\
\hline
\end{tabular}

Fuente: elaboración propia sobre la base de datos del Programa de las Naciones Unidas para el Desarrollo (PNUD).

a Jerarquía entre 187 países (PNUD-2013).

b Jerarquía entre 117 países (cálculos propios). 


\section{Bibliografía}

Benavides, Jorge (2012), "Índice de democracia", Boletín, $\mathrm{N}^{\circ} 36$, Fundación para el Desarrollo de Guatemala (FUNDESA), enero [en línea] http://www.fundesa.org.gt/cms/content/files/ publicaciones/Boletin_de_Desarrollo_Democracy_Index.pdf.

Economist Intelligence Unit (2013), "Democracy Index 2012 Democracy at a Standstill" [en línea] https://portoncv.gov.cv/ dhub/porton.por_global.open_file?p_doc_id=1034.

(2010), "Democracy Index 2010. Democracy in retreat" [en línea] http://graphics.eiu.com/PDF/Democracy_Index_2010_ web.pdf.

Hernández, Ángel (2008), "El desarrollo humano", El desarrollo como problema: ¿Igualdad de qué?, Ángel Hernández (comp.), Caracas, Consejo de Desarrollo Científico y Humanístico.

Johnson, Lawrence (2010), "Aumento del empleo vulnerable y la pobreza: Entrevista con el jefe de la unidad de las tendencias mundiales del empleo de la oIT" [en línea] http://www.ilo. org/global/about-the-ilo/newsroom/features/WCMS_120473/ lang--es/index.htm.

Klugman, Jeni, Francisco Rodríguez y Hyung-Jin Choi (2011), “IDH 2010: Nuevas controversias, nuevas críticas", Programa de las Naciones Unidas para el Desarrollo [en línea] http://hdr.undp. org/es/desarrollohumano/hablemos-dh/2011-04/.

OIT (Organización Internacional del Trabajo) (2013b), "La importancia del empleo y los medios de vida en la agenda para el desarrollo con posterioridad a 2015" [en línea] http:// www.ilo.org/wcmsp5/groups/public/---dgreports/---dcomm/ documents/statement/wcms_206443.pdf.

(2012), "Informe sobre el trabajo en el mundo, 2012. Resumen de España" [en línea] http://www.ilo.org/wcmsp5/ groups/public/---dgreports/---dcomm/documents/briefingnote/ wcms_179517.pdf.

PNUD (Programa de las Naciones Unidas para el Desarrollo) (2013), "Indicadores y datos" [en línea] http://hdrstats.undp.org/es/ indicadores/103106.html.
(2010), Informe sobre desarrollo humano, 2010. La verdadera riqueza de las naciones: Camino al desarrollo humano, Nueva York [en línea] http://hdr.undp.org/es/informes/ mundial/idh2010/capitulos/es/.

(2002), Informe sobre desarrollo humano, 2002. Profundizar la democracia en un mundo fragmentado, Nueva York [en línea] http://www.dhl.hegoa.ehu.es/ficheros/0000/0426/ Informe_DH._Profundizar_democracia.pdf.

(2000), Informe sobre desarrollo humano en Venezuela, 2000. Caminos para superar la pobreza [en línea] http://hdr. undp.org/sites/default/files/venezuela_2000_sp.pdf.

(1992), Informe sobre desarrollo humano, 1992. Una nueva visión sobre desarrollo humano internacional [en línea] http://hdr.undp.org/es/content/informe-sobre-desarrollohumano-1992.

(1990), Informe sobre desarrollo humano, 1990. Concepto y medición del desarrollo humano [en línea] http://hdr.undp. org/es/informes/mundial/idh1990/capitulos/espanol/.

Recalde, Diego (1999), El desarrollo humano sostenible, Medellín, Universidad Nacional de Colombia [en línea] http://www. google.co.ve/url? $\mathrm{sa}=\mathrm{t} \& \mathrm{rct}=\mathrm{j} \& \mathrm{q}=\&$ esrc $=\mathrm{s} \&$ source $=$ web $\& \mathrm{~cd}=$ $1 \&$ ved=0CC4QFjAA\&url=http $\% 3 \mathrm{~A} \% 2 \mathrm{~F} \% 2$ Fmedia.wix.com \%2Fugd\%2F83433d_8bdaec06cf56b43b8ed8aee2d6273487. pdf\%3Fdn\%3DFor9-3-Recalde.PDF\&ei=tg_QUtHhDYbMs QSfz4HwCw\&usg=AFQjCNGX3ZX1VS2nfIcIz5vJXqXwI Z8z0Q\&sig2=_TkrHcPPTqoRlcZnhTNtPQ\&bvm=bv.59026 428, d.cWc

Sen, Amartya (2000), Desarrollo y libertad, México, D.F., Planeta. Vethencourt, Fabiola (2008), "La perspectiva de las capacidades de Amartya Sen", El desarrollo como problema: ¿Igualdad de qué?, Ángel Hernández (comp.), Caracas, Consejo de Desarrollo Científico y Humanístico. 